DOI: 10.26730/1999-4125-2021-3-104-112

УДК 622.271.3

ОЦЕНКА СТЕПЕНИ ВЗАИМОВЛИЯНИЯ ВМЕСТИМОСТИ КОВША ЭКСКАВАТОРА И КУЗОВА АВТОСАМОСВАЛА

\title{
ESTIMATION OF THE DEGREE OF MUTUAL INFLUENCE OF THE EXCAVATOR BUCKET CAPACITY AND HAUL TRUCK BODY
}

\author{
Хорешок Алексей Алексеевич, \\ докт. техн. наук, проф., е-mail: haa.omit@ kuzstu.ru \\ Alexey A. Khoreshok, Dr.Sc. (Tech.), Professor \\ Дубинкин Дмитрий Михайлович, \\ канд. техн. наук, доцент, e-mail: ddm.tm@ @uzstu.ru \\ Dmitry M. Dubinkin, Ph.D., Associate Prof. \\ Марков Сергей Олегович, \\ канд. техн. наук, доцент, e-mail: markovso@ kuzstu.ru \\ Sergey O. Markov, Ph.D., Associate Prof. \\ Тюленев Максим Анатольевич, \\ канд. техн. наук, проф., e-mail: tma.geolog@kuzstu.ru \\ Maxim A. Tyulenev, Ph.D., Prof.
}

Кузбасский государственный технический университет имени Т.Ф. Горбачева, 650000, Россия, г. Кемерово, ул. Весенняя, 28

T.F. Gorbachev Kuzbass State Technical University, 28 Vesennyaya street, Kemerovo, 650000, Russian Federation

\section{Аннотация:}

Из классических трудов по горному делу известно давно установленное рациональное соотношение вместимости ковша экскаватора и кузова автосамосвала - 4-6 ковшей. Эта величина была получена на основе анализа опыта совместной работы оборудования в реальных условиях еще в 60-х годах прошлого столетия и с тех пор практически не подвергалась корректировке. Однако следует отметить факт, что в то время не было такого разнообразия типоразмеров оборудования, особенно это касается автосамосвалов. Кроме того, появился новый тип выемочно-погрузочного оборудования: гидравлические экскаваторы, для которых данное соотношение было принято, по сути, автоматически. В данной статье представлены результаты предварительного исследования взаимовлияния вместимости ковша экскаватора и кузова автосамосвала с точки зрения изменения эффективной производительности этих горных машин. Для анализа использовались экскаваторы одной и той же фирмы-производителя с

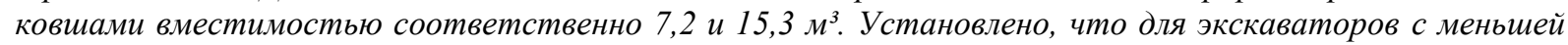
вместимостью ковша производительность не имеет ярко выраженной зависимости от вместимости кузова автосамосвала, в то время как для более крупных моделей разница может доходить до 25\% и более при применении автосамосвалов грузоподъемностью, в частности, 55 и 90 m. Также рассмотрен вариант расчета эффективной производительности отдельно взятой модели экскаватора с тремя разными автосамосвалами. Сделан вывод о том, что необходим более детализированный расчет параметров экскаваторно-автомобильного комплекса для обеспечения его эффективной работы.

Ключевые слова: Открытые горные работы, гидравлические экскаваторы, мехлопаты, карьерные автосамосваль,, экскаваторно-автомобильный комплекс, автономные тяжелье платформы, производительность экскаваторов, производтельность автосамосвалов.

Информация о статье: поступило в редакцию 01.06.2021

Abstract:

From the classic works on open pit mining we know the long-established rational combination of excavator bucket capacity and haul truck body - 4-6 buckets. This value was obtained by analyzing the experience of joint operation of the equipment in real conditions back in the 60s of the last century, and since then practically has not been subjected to adjustment. However, we should note the fact that at that time there was not such a variety 
of equipment sizes, especially for haul trucks. In addition, a new type of excavation and loading equipment appeared: hydraulic excavators, for which this ratio was accepted, in fact, automatically. This article presents the results of a preliminary study of the mutual influence of excavator bucket capacity and haul truck body in terms of changes in the effective productivity of these mining machines. For the analysis we used excavators of the same manufacturer with a bucket capacity of 7.2 and $15.3 \mathrm{~m}^{3}$, respectively. It is established that for excavators with smaller bucket capacity the productivity doesn't have strongly pronounced dependence on haul truck body capacity while for larger models the difference can reach up to $25 \%$ and more at application of haul trucks with carrying capacity, in particular, 55 and 90 tons. Also, the variant of the effective productivity calculation of the single excavator model with three different haul trucks is considered. It is concluded that a more detailed calculation of the parameters of excavator-truck complex to ensure its effective operation is necessary.

Keywords: Open-pit mining, hydraulic excavators, rope shovels, haul trucks, excavator-truck complex, autonomous heavy trucks, productivity of excavators, productivity of haul trucks.

Article info: received June 01, 2021

\section{Введение}

На существующих и перспективных разрезах основной является транспортная технология ведения горных работ с применением экскаваторов (канатных и гидравлических) и карьерных автосамосвалов [1-9]. Доля экскаваторов различных типов в общем парке выемочного оборудования варьируется достаточно широко [10-12], но общая тенденция выражена достаточно четко - в безугольной зоне применяются мощные мехлопаты, а также в последнее время - прямые гидролопаты [13-15]. Обратные гидролопаты, особенно с небольшой вместимостью ковша, используются для отработки угленасыщенных зон [16-20]. При работе по транспортной технологии как гидравлических, так и канатных экскаваторов, наблюдаются потери времени при обмене автосамосвалов под экскаватором. Условно говоря, не выработано единого мнения о том, стоит ли считать это потерями времени или нет. Физический смысл вполне ясен: груженый автосамосвал трогается с места, перемещается по призабойной зоне и отъезжает на отвал (либо, соответственно, угольный склад). В это время подъехавший порожний автосамосвал начинает маневры, чаще всего - сдает задним ходом к месту установки. Если задаться средним временем обмена, равным одной минуте, то в этот

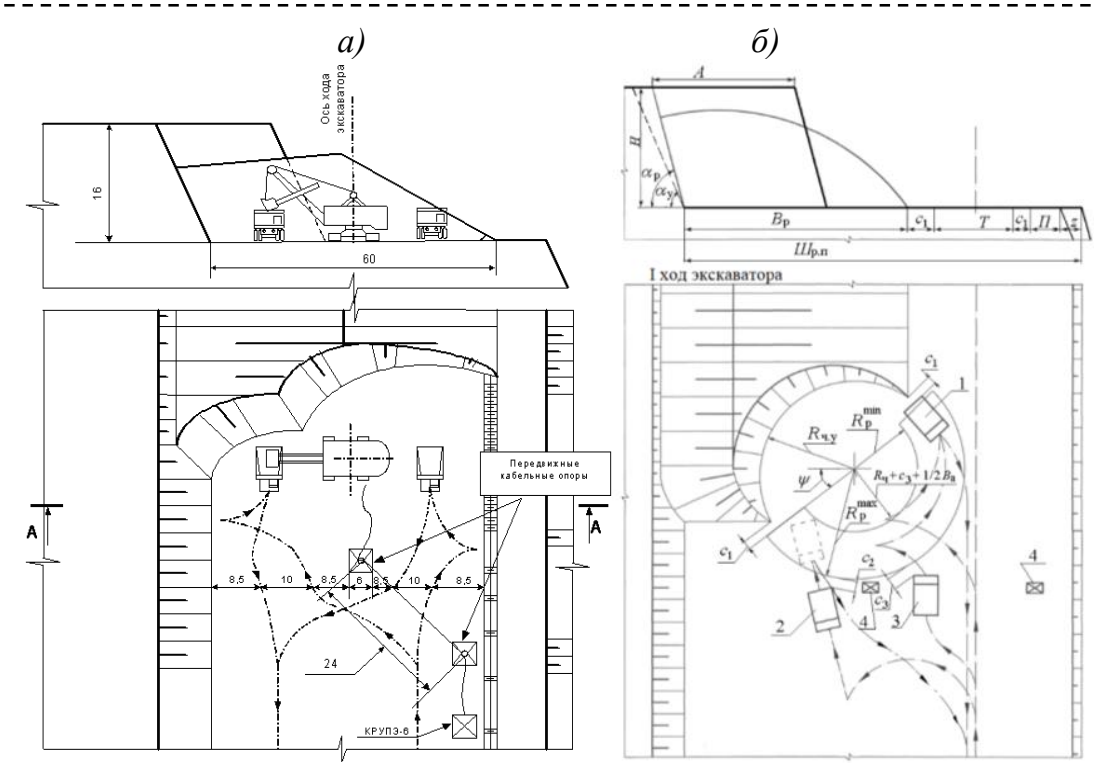

Рис. 1. Схемы отработки развала взорванной горной массы прямыми мехлопатами: а - на разрезе «Бачатский», б-на разрезе «Кедровский» [2]. На рис. 1-б: 1, 2, 3-места установки автосамосвалов при погрузке, ожидании погрузки и ожидании начала маневрирования соответственно; 4 передвижные кабельные ворота.

Fig. 1. Schemes for working out the breakup of the blasted rock mass with straight shovels: a - at the Bachatskiy open-pit, $b$ - at the Kedrovskiy open-pit [2]. In fig. 1-b: 1, 2, 3 - dump trucks installation places during loading, waiting for loading and waiting for the start of maneuvering, respectively; 4 - movable cable gates. 
промежуток времени экскаватор успевает совершить цикл черпания (примерно 30 секунд) и с наполненным ковшом, выставленным по месту погрузки, ожидает автосамосвал. Это еще 30 секунд.

Следует отметить, что рассмотренная ситуация характерна по большей части для канатных экскаваторов, поскольку гидравлические, как правило, могут успеть во время ожидания автосамосвала подчистить подъезд и т.д., то есть использовать время на вспомогательные работы. При работе же мехлопат чистка подъезда выполняется обычно бульдозером с периодичностью один-два раза за смену.

\begin{tabular}{|c|c|c|c|c|c|c|c|c|}
\hline \multirow{2}{*}{ Показатели } & \multicolumn{8}{|c|}{ Вместимость ковша экскаватора, м $^{3}$} \\
\hline & 2,5 & 2,5 & 2,8 & 2,8 & 3,1 & 3,1 & 4 & 4 \\
\hline $\begin{array}{l}\text { Грузоподъемность } \\
\text { автосамосвала, т }\end{array}$ & 45,0 & 55,0 & 45,0 & 55,0 & 45,0 & 55,0 & 45,0 & 55,0 \\
\hline $\begin{array}{l}\text { Объем кузова «с шапкой», } \\
\text { м }^{3}\end{array}$ & 26,3 & 32,3 & 26,3 & 32,3 & 26,3 & 32,3 & 26,3 & 32,3 \\
\hline $\begin{array}{l}\text { Количество циклов при } \\
\text { погрузке }\end{array}$ & 10,0 & 12,0 & 9,0 & 10,0 & 8,0 & 9,0 & 6,0 & 7,0 \\
\hline $\begin{array}{l}\text { Время погрузки одной } \\
\text { единицы, мин }\end{array}$ & 5,0 & 6,0 & 4,5 & 5,0 & 4,0 & 4,5 & 3,0 & 3,5 \\
\hline $\begin{array}{l}\text { Время простоя экскаватора } \\
\text { при ожидании } \\
\text { автосамосвалов, ч/год }\end{array}$ & 497,5 & 420,9 & 547,2 & 497,5 & 608,0 & 547,2 & 781,7 & 684,0 \\
\hline $\begin{array}{l}\text { Грузоподъемность } \\
\text { автосамосвала, т }\end{array}$ & 45,0 & 55,0 & 45,0 & 55,0 & 45,0 & 55,0 & 45,0 & 55,0 \\
\hline $\begin{array}{l}\text { Количество циклов при } \\
\text { погрузке }\end{array}$ & 6,0 & 7,0 & 5,0 & 5,0 & 5,0 & 5,0 & 4,0 & 4,0 \\
\hline $\begin{array}{l}\text { Объем кузова «с шапкой», } \\
\text { м³ }^{3}\end{array}$ & 26,3 & 32,3 & 26,3 & 32,3 & 26,3 & 32,3 & 26,3 & 32,3 \\
\hline $\begin{array}{l}\text { Время погрузки одной } \\
\text { единицы, мин }\end{array}$ & 3,0 & 3,5 & 2,5 & 2,5 & 2,5 & 2,5 & 2,0 & 2,0 \\
\hline $\begin{array}{l}\text { Время простоя экскаватора } \\
\text { при ожидании } \\
\text { автосамосвалов, ч/год }\end{array}$ & 781,7 & 684,0 & 912,0 & 912,0 & 912,0 & 912,0 & 1094,4 & 1094,4 \\
\hline
\end{tabular}

Подобного недостатка лишены схемы с двусторонней подачей автосамосвалов под погрузку. При работе мехлопат для обеспечения такой работы используются так называемые кабельные ворота (или «передвижные кабельные опоры»), представляющие собой две металлические мачты, на которые лебёдками поднимается высоковольтный кабель, что позволяет обеспечить двухсторонний доступ к экскаватору для погрузки горной массы.

Схемы работы экскаваторов-мехлопат на двустороннюю погрузку показаны на рис. 1-a, б (разрезы «Бачатский» и «Кедровский» соответственно).

Но данная технология не получила широкого применения по ряду причин. Во-первых, подавляющее большинство технологических схем работы прямых мехлопат проектируются под тупиковую схему разворота автотранспорта с целью снижения ширины рабочей площадки; следовательно, возникают проблемы как с размещением кабельных ворот, так и с обеспечением разворота двух автосамосвалов. Во-вторых, при установке автосамосвала с левой стороны экскаватора затрудняется обзор машиниста. Кроме того, возникают проблемы с размещением негабарита, перемещением его ковшом экскаватора и т.д.

Поэтому при работе прямых мехлопат возникает прямое недоиспользование рабочего времени из-за его потерь на обмен автосамосвалов, обусловленное объективными причинами. 
Гидравлические экскаваторы вследствие своей независимости от источника электроэнергии лишены таких проблем, однако снижение времени обмена автосамосвалов является не менее актуальной задачей при использовании этого вида выемочно-погрузочного оборудования.

\section{Материалы и методы}

Для установления потерь времени при работе гидравлических экскаваторов нами была ранее выполнена [3] примерная оценка данных с учетом взаимного соотношения ковша экскаватора и кузова автосамосвала: наиболее часто применяемые модели экскаваторов (в данном случае - обратных гидравлических лопат) с вместимостью ковша от 2,5 до $6,7 \mathrm{~m}^{3}$ и автосамосвалов с грузоподъемностью 45 и 55 т (БелАЗ-75473 и БелАЗ-7555В).

Результаты расчета представлены в табл. 1 [3].

Анализ данных таблицы показал, что чем меньше циклов требуется совершить экскаватору при погрузке горной массы (т.е. меньшее число ковшей на загрузку одного автосамосвала), тем больше доля времени, приходящегося на ожидание порожнего автосамосвала под погрузку. Возникает дилемма: с одной стороны, стремятся минимизировать время погрузки за счет меньшего числа ковшей, приходящихся на одну единицу автотранспорта для роста его производительности, с другой - эта минимизация приводит к снижению эффективной производительности экскаваторов.

Причем при снижении производительности экскаваторов производительность автосамосвала (при прочих равных условиях) будет расти за счет меньшего времени погрузки и, соответственно, меньшего времени рейса. Следовательно, необходимо выполнить более детализированный расчет производительности выемочного и транспортного оборудования с учетом вышеуказанных особенностей.

\section{Результаты и обсуждение}

При погрузке одних и тех же автосамосвалов экскаваторами, имеющими различную вместимость ковша, эксплуатационная производительность последних будет одинакова. Поэтому для определения потерь времени необходимо в расчетах использовать не эксплуатационную, а эффективную производительность. Выразим ее через число автосамосвалов, загружаемых в течение смены, и как результат - объем горной массы, перевезенной этим числом автосамосвалов.

Сделаем некоторые допущения: для удобства расчетов примем время цикла экскаватора $t_{u}$ равным 30 секундам. Экскаваторы - Liebherr R984C $\left(\mathrm{E}=7.2 \mathrm{M}^{3}\right)$, Liebherr R9350 $\left(\mathrm{E}=15.3 \mathrm{~m}^{3}\right)$; автосамосвалы - БелАЗ-7555В и БелАЗ-7558В грузоподъемностью 55 и 90 тонн и вместимостью кузова «с шапкой» 35.3 и 60 м $^{3}$ соответственно.

Тогда получаются следующие варианты:

1. Погрузка экскаватором Liebherr R984C автосамосвала БелАЗ-7555B;

2. Погрузка экскаватором Liebherr R984C автосамосвала БелА3-7558B;

3. Погрузка экскаватором Liebherr R9350 автосамосвала БелА3-7555B;

4. Погрузка экскаватором Liebherr R9350 автосамосвала БелАЗ-7558B.

Число ковшей, загружаемых в автосамосвалы:

$$
n_{\kappa}=\left[\frac{V_{a}}{E}\right],
$$

где $V_{a}$ - вместимость кузова автосамосвала, $E$ - вместимость ковша экскаватора.

Тогда по вариантам $1 . . .4$ число ковшей будет соответственно 5, 9, 3 и 4 ковша.

Следовательно, максимально возможное число автосамосвалов $N_{a . c м(i)}$, загружаемых за час, будет равно ( $i-$ номер варианта):

$$
N_{a . c u(1)}=\frac{60}{n_{\kappa} \cdot t_{u}+t_{\text {ож }}}=\frac{60}{5 \cdot 0.5+0.5}=20
$$


Вестник Кузбасского государственного технического университета. 2021. № 3, с.104-112

108 Хорешок А.А., Дубинкин Д.М., Марков С.О., Тюленев М.А. Оценка степени взаимовлияния...

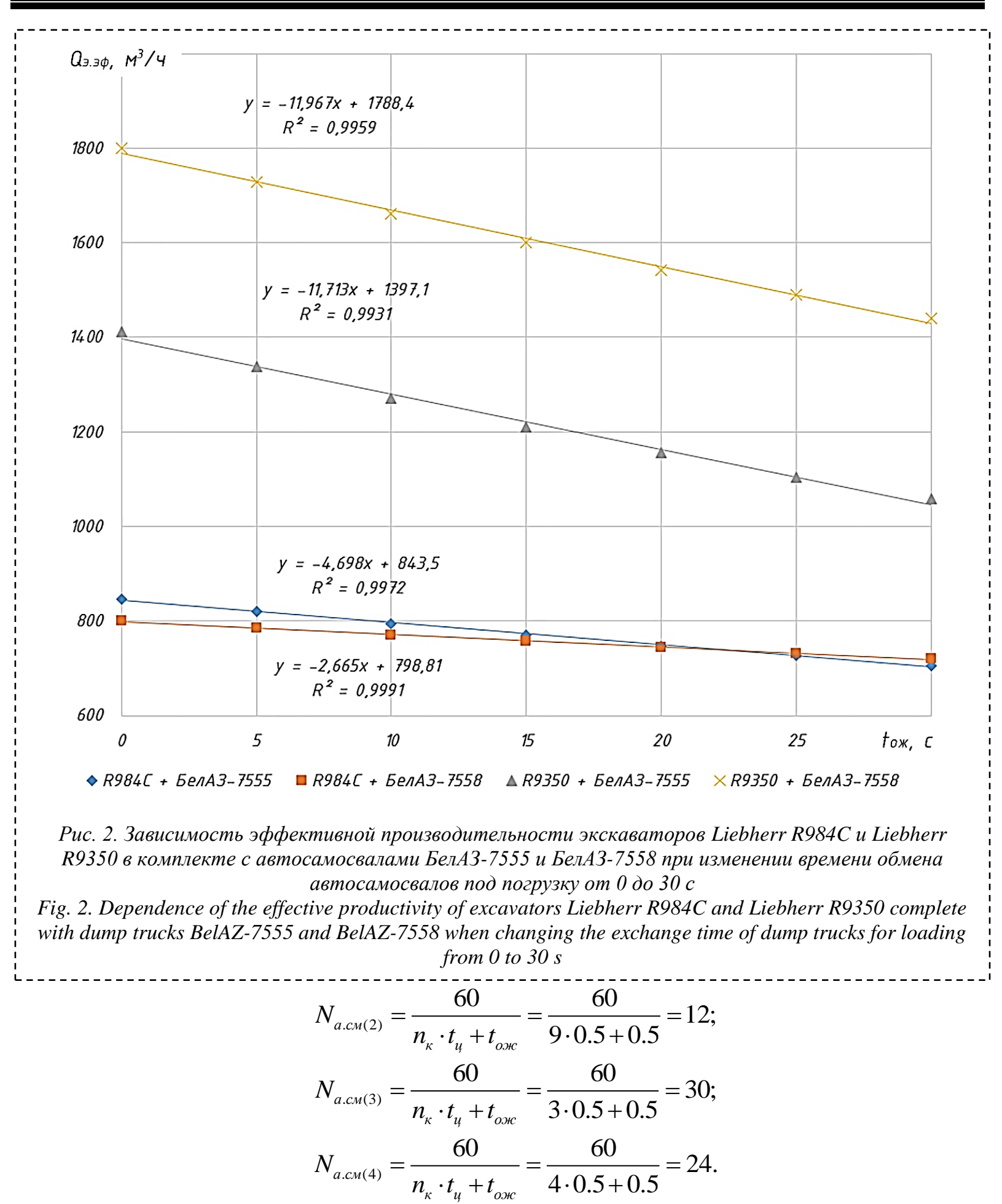

Часовая эффективная производительность в этом случае равна:

$$
\begin{aligned}
& Q_{\text {ээф }(1)}=N_{a . c m(R 984)} \cdot V_{a(7555)}=20 \cdot 35.3=706{ }_{\mathrm{M}^{3} / \mathrm{4}} \text {; } \\
& Q_{\text {э.эф(2) }}=N_{a . c \mathrm{M}(R 984)} \cdot V_{a(7558)}=12 \cdot 60=720_{\mathrm{M}^{3} / \mathrm{u}} ; \\
& Q_{э . э \phi(3)}=N_{a . c m(R 9350)} \cdot V_{a(7555)}=30 \cdot 35.3=1059 \mathrm{M}^{3 / 4} \text {; } \\
& Q_{\text {э.эф(4) }}=N_{a . c м(R 9350)} \cdot V_{a(7558)}=24 \cdot 60=1440_{\mathrm{M}^{3} / \mathrm{ч}} .
\end{aligned}
$$

Результаты говорят о более резком росте эффективной производительности у большей модели экскаватора.

Далее выполним расчет эффективной часовой производительности экскаватора с учетом 


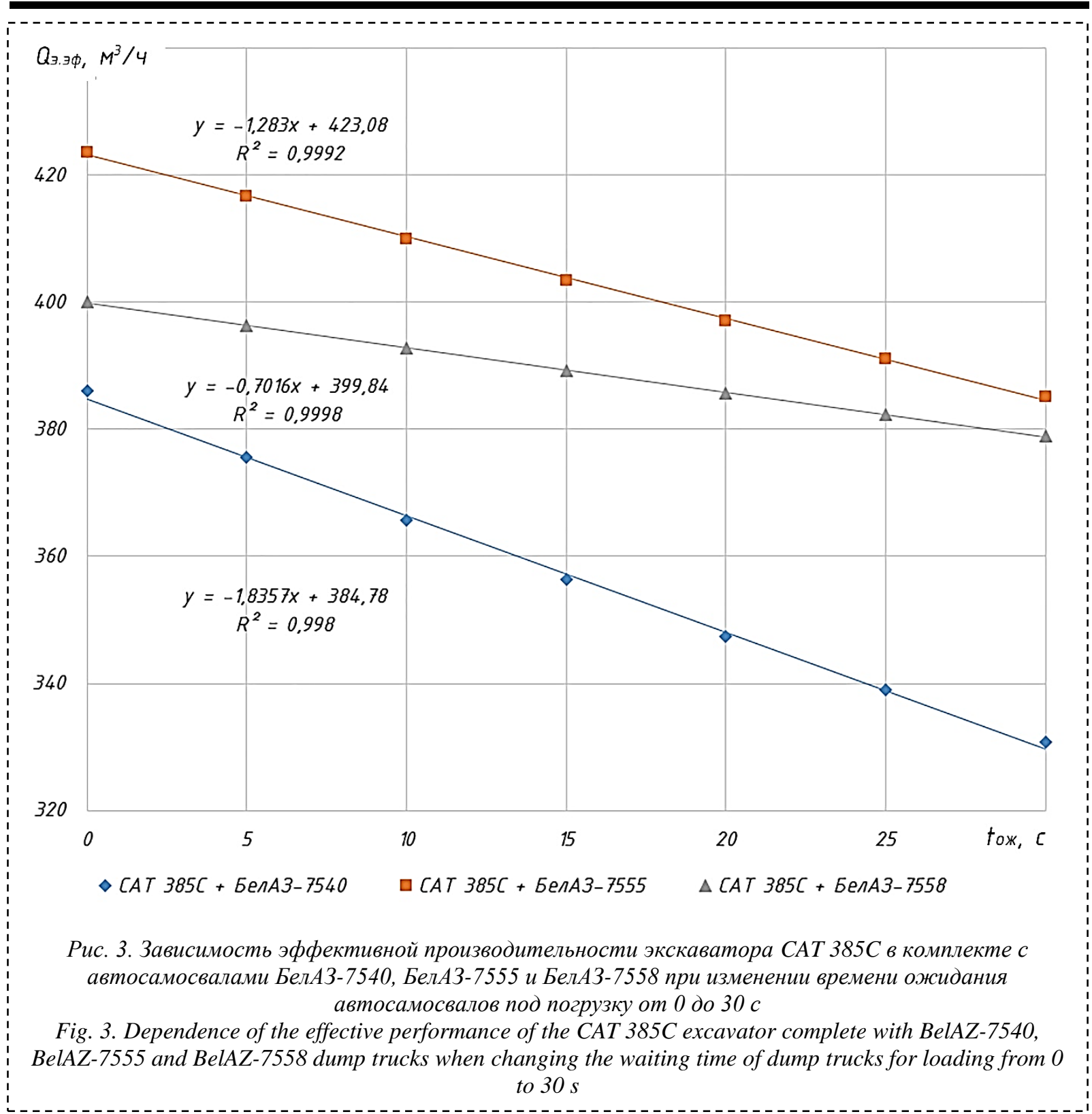

потенциально возможного снижения времени на обмен автосамосвалов под погрузку (времени ожидания автосамосвала с наполненным ковшом). Шаг снижения $-5 \mathrm{c}$, время варьируется от 30 с (базовый вариант) до 0 с (максимально достижимый, например, при использовании конвейерного транспорта).

Результаты расчета представлены на рис. 2.

Из анализа рис. 2 следует, что максимальная эффективная производительность экскаватора Liebherr R9350 достигается при применении более крупной модели автосамосвала и снижается по экспоненциальной зависимости с ростом времени обмена транспортных средств. Для экскаватора Liebherr R984 картина несколько иная: при времени обмена до 20 с эффективная производительность будет выше при применении автосамосвалов меньшей грузоподъемности; при времени обмена 25-30 с (и более) производительность будет выше при работе с более крупными автосамосвалами.

На основании этого можно сделать вывод о неоднозначности степени взаимовлияния вместимости ковша экскаватора и кузова автосамосвала. В частности, для экскаватора Liebherr $\mathrm{R} 984 \mathrm{C}$ изменение производительности при применении автосамосвалов, различающихся по вместимости кузова почти в два раза (и, соответственно, 5 и 9 ковшей), составляет 2-6\%, а для Liebherr R9350 для тех же условий - уже 27-36\%.

Рассмотрим вариант использования гидравлического экскаватора САТ 385C (вместимость 
ковша 3,5 м³) с тремя различными марками автосамосвалов: БелАЗ-7540, БелАЗ-7555 и БелАЗ7558 с вместимостью кузова 19.3, 35.3 и $60 \mathrm{~m}^{3}$ соответственно. Расчет производительности был выполнен аналогично предыдущему примеру; время экскаваторного цикла также принималось равным 30 с. Число ковшей для погрузки этих моделей автосамосвалов составило 6, 10 и 18 соответственно.

Результаты расчета представлены графически на рис. 3.

Анализ показывает, что максимальная эффективная производительность для указанных выше горнотехнических условий достигается при совместной работе САТ 385C и автосамосвала БелАЗ-7555, т.е. «средней» модели из рассматриваемых. При увеличении времени обмена самосвалов снижение производительности происходит весьма неравномерно по всем рассмотренным вариантам; чем меньше вместимость кузова автосамосвала, тем интенсивнее снижается производительность. Кроме того, при времени ожидания $41.7 \mathrm{c}$ производительность САТ $385 \mathrm{C}$ будет одинаковой при погрузке в самосвалы грузоподъемностью 55 и 90 т, из чего следует, что при времени простоя экскаватора более 42 с целесообразно использовать большие по грузоподъёмности автосамосвалы.

\section{Выводы}

1. В связи с современным многообразием марок и моделей выемочно-погрузочного и горнотранспортного оборудования необходима корректировка рационального соотношения вместимости кузова автосамосвала и ковша экскаватора при комплексном учете горнотехнических факторов, прямо или косвенно влияющих на возможное изменение эффективной производительности выемочно-погрузочного оборудования: физикомеханические и физико-технические свойства экскавируемых горных пород, вид погрузки горной массы (взаимное расположение экскаватора и автосамосвала на уступе), изменение времени цикла экскаватора и т.д.

2. При рассмотрении одиночной модели экскаватора в комплексе с автосамосвалами различной грузоподъемности установлено, что эффективная производительность имеет линейный характер снижения в зависимости от увеличения времени ожидания, причем снижение происходит неравномерно для разных марок автосамосвалов; также наблюдаются определенные значения времени ожидания, при которых производительность экскаватора будет одинаковой для автосамосвалов с различной вместимостью кузова.

3. Интенсивность снижения производительности (как первая производная от функциональной зависимости, представленной на рис. 3) для БелАЗ-7558 составляет $\Delta Q_{\text {э.эф }}=-$ $0.7016 \mathrm{~m}^{3} /$ ч, для БелАЗ-7555 $\Delta Q_{\text {ээ } \phi}=-1.283 \mathrm{~m}^{3} /$ ч, для БелАЗ-7540 $\Delta Q_{\text {ээф }}=-1.8357 \mathrm{~m}^{3} /$ ч, т.е. чем меньше грузоподъемность автосамосвала, тем интенсивнее снижается производительность экскаватора при увеличении времени простоев. Это связано с увеличением в единицу времени числа загруженных автосамосвалов и, как следствие, простоев экскаватора при ожидании обмена автосамосвалов.

4. Необходим дальнейший детализированный расчет оптимальных показателей погрузки, учитывающий максимально возможное количество факторов, оказывающих влияние на работу экскаваторно-автомобильного комплекса, для чего предполагается проведение полномасштабных натурных экспериментов.

Работа выполнена при финансовой поддержке Министерства науки и выстего образования Российской Федерачии в рамках соглашения № 075-11-2020-031 от 14.12.2020 г. с ПАО «КАМАЗ» по комплексному проекту «Создание высокотехнологичного производства семейства роботизированных карьерных самосвалов грузоподъемностью до $90 \mathrm{~m} c$ электромеханической трансмиссией на основе иифровых технологий», при участии ФГБОУ ВО «Кузбасский государственный технический университет имени Т.Ф. Горбачева» в части выполнения научно-исследовательских, опытно-конструкторских и технологических работ. 


\section{СПИСОК ЛИТЕРАТУРЫ}

1. Шешко, Е. Е. Горно-транспортные машины и оборудование для открытых работ: Учеб. пособие для вузов. - 3-е изд., перераб. и доп. // М.: МГГУ. - 2003. - 260 с.

2. Колесников, В.Ф. Применение экскаваторов большой производственной мощности на разрезах Кузбасса / В.Ф. Колесников, А.И. Корякин // Вестник КузГТУ. - 2012. - №4. - С. 24-25.

3. Дубинкин, Д.М. Исследование процесса транспортирования вскрышных пород и угля на разрезах / Д.М. Дубинкин, В.Ю. Садовец, Г.О. Котиев, А.В. Карташов // Техника и технология горного дела. 2019. - №4. - С. 50-66.

4. Васильев, М.В. Транспортные процессы и оборудование на карьерах // М.: Недра. - 1986. - 240 с.

5. Зырянов, И.В. Производительность выемочно-погрузочного оборудования / И.В. Зырянов, Ю.И. Лель, Д.Х. Ильбульдин, Н.В. Мартынов, Р.С. Ганиев // Известия высших учебных заведений. Горный журнал. - 2016. - № 8. - С. 11-20.

6. Дубинкин, Д.М. Обоснование необходимости создания тяжелых платформ для открытых горных работ // Горное оборудование и электромеханика. - 2020. - №4 (150). - С. 59-64.

7. Сандригайло, И.Н. Анализ эффективности применения шарнирно-сочлененных автосамосвалов при разработке месторождений с малыми запасами / И.Н. Сандригайло, С.А. Арефьев, Х.С. Мойсиев, И.А. Глебов, Д.А. Шлохин // Известия УГГУ. - 2015. - № 2. - С. 23-27.

8. Яковлев, В.Л. Основные аспекты формирования и новые научные направления исследований транспортных систем карьеров / В.Л. Яковлев, Ю.А. Бахтурин, А.Г. Журавлев // Наука и образование. 2015. - № 4. - С. 67-72.

9. Анистратов, К.Ю. Исследование закономерностей изменения показателей работы карьерных автосамосвалов в течение срока их эксплуатации / К.Ю. Анистратов, М.С. Градусов, В.Я. Стремилов, М.В. Тетерин // Горная промышленность. - 2006. - №6. - С. 30-34.

10.Гавришев, С.Е. Повышение эффективности использования автосамосвалов в условиях карьеров на открытых горных работах / С.Е. Гавришев, А.Д. Кольга, И.А. Пыталев, Т.М. Попова // Известия Тульского государственного университета. Науки о Земле. - 2019. - № 3. - С. 161-170.

11.Подэрни, Р.Ю. Мировой рынок поставок современного выемочно-погрузочного оборудования для открытых горных работ / Горный информационно-аналитический бюллетень (научно-технический журнал). - 2015. - №2. - С. 148-167.

12.Сытенков, В.Н. Анализ областей применения канатных и гидравлических экскаваторов при открытой разработке месторождений / В.Н. Сытенков, А.Р. Ганин, Т.В. Донченко, Д.А. Шибанов // Рациональное освоение недр. - 2014. - №3. - С. 30-37.

13.Колесников, В.Ф. Обзор ведения выемочно-погрузочных работ при отработке угленасыщенных зон разрезов Кузбасса / В.Ф. Колесников, М. Цехлар Е.А. Тюленева // Техника и технология горного дела. - 2018. - № 2 (2). - С. 36-50.

14.Подэрни, Р.Ю. Сравнительный анализ гидравлических и механических экскаваторов с прямой лопатой / Р.Ю. Подэрни, П. Булес // Горный журнал. - 2015. - № 1. С. 55-61.

15.Страбыкин, Н.Н. Основные направления технической политики в области развития экскаваторостроения для карьеров / Н.Н. Страбыкин, В.М. Горячкин // Горное оборудование и электромеханика. - 2012. - №3. - С. 36-44.

16.Литвин, О.И. Обоснование рациональных технологических параметров производства вскрышных работ обратными гидравлическими лопатами на разрезах Кузбасса: дис. ... канд. техн. наук. - Кемерово, 2012. - 119 c.

17.Litvin O. Study of the backhoe's digging modes at rock face working-out / O. Litvin, V. Makarov, A. Strelnikov, E. Tyuleneva // E3S Web of Conferences. - 2019. - Vol. 105. - Article no. 01024.

18.Кантович, Л.И. Опыт и перспективы применения гидравлических экскаваторов при отработке угленасыщенных зон на разрезах Кузбасса / Л.И. Кантович, О.И. Литвин, А.А. Хорешок, Е.А. Тюленева // Горный информационно-аналитический бюллетень (научно-технический журнал). $-2019 .-$ № 4. - С. 152-160.

19.Тюленев, М.А. Об интенсивности изменения производительности автономной тяжелой платформы / М.А. Тюленев, С.О. Марков, Д.М. Дубинкин, В.В. Аксенов // Вестник КузГТУ. - 2021. №1. - С. 97-108.

20.Дубинкин, Д.М. Влияние горнотехнических факторов на производительность беспилотных карьерных автосамосвалов / Д.М. Дубинкин, В.В. Аксенов, М.А. Тюленев, С.О. Марков // Техника и технология горного дела. - 2020. - № 4 (11). - С. 42-69. 


\section{REFERENCES}

1. SHeshko E E Gorno transportnye mashiny i oborudovanie dlya otkrytyh rabot Ucheb posobie dlya vuzov 3 e izd pererab i dop M MGGU 2003260 s

2. Kolesnikov V F Primenenie ehkskavatorov bolshoj proizvodstvennoj moshchnosti na razrezah Kuzbassa V F Kolesnikov A I Koryakin Vestnik KuzGTU 20124 C 2425

3. Dubinkin D M Issledovanie processa transportirovaniya vskryshnyh porod i uglya na razrezah D M Dubinkin V YU Sadovec G O Kotiev A V Kartashov Tekhnika i tekhnologiya gornogo dela 20194 C 5066

4. Vasilev M V Transportnye processy i oborudovanie na karerah M Nedra $1986240 \mathrm{~s}$

5. Zyryanov I V Proizvoditelnost vyemochno pogruzochnogo oborudovaniya I V Zyryanov YU I Lel D H Ilbuldin N V Martynov R S Ganiev Izvestiya vysshih uchebnyh zavedenij Gornyj zhurnal 20168 S 1120

6. Dubinkin D M Obosnovanie neobhodimosti sozdaniya tyazhelyh platform dlya otkrytyh gornyh rabot Gornoe oborudovanie i ehlektromekhanika 20204150 S 5964

7. Sandrigajlo I N Analiz ehffektivnosti primeneniya sharnirno sochlenennyh avtosamosvalov pri razrabotke mestorozhdenij s malymi zapasami I N Sandrigajlo S A Arefev H S Mojsiev I A Glebov D A SHlohin Izvestiya UGGU 20152 S 2327

8. YAkovlev V L Osnovnye aspekty formirovaniya $\mathrm{i}$ novye nauchnye napravleniya issledovanij transportnyh sistem karerov V L YAkovlev YU A Bahturin A G ZHuravlev Nauka i obrazovanie 20154 S 6772

9. Anistratov K YU Issledovanie zakonomernostej izmeneniya pokazatelej raboty karernyh avtosamosvalov v techenie sroka ih ehkspluatacii K YU Anistratov M S Gradusov V YA Stremilov M V Teterin Gornaya promyshlennost $20066 \mathrm{~S} 3034$

10. Gavrishev S E Povyshenie ehffektivnosti ispolzovaniya avtosamosvalov $\mathrm{v}$ usloviyah karerov na otkrytyh gornyh rabotah S E Gavrishev A D Kolga I A Pytalev T M Popova Izvestiya Tulskogo gosudarstvennogo universiteta Nauki o Zemle 20193 S 161170

11. Podehrni R YU Mirovoj rynok postavok sovremennogo vyemochno pogruzochnogo oborudovaniya dlya otkrytyh gornyh rabot Gornyj informacionno analiticheskij byulleten nauchno tekhnicheskij zhurnal 20152 S 148167

12. Sytenkov V N Analiz oblastej primeneniya kanatnyh i gidravlicheskih ehkskavatorov pri otkrytoj razrabotke mestorozhdenij V N Sytenkov A R Ganin T V Donchenko D A SHibanov Racionalnoe osvoenie nedr 20143 S 3037

13. Kolesnikov V F Obzor vedeniya vyemochno pogruzochnyh rabot pri otrabotke uglenasyshchennyh zon razrezov Kuzbassa V F Kolesnikov M Cekhlar E A Tyuleneva Tekhnika i tekhnologiya gornogo dela 201822 S 3650

14. Podehrni R YU Sravnitelnyj analiz gidravlicheskih i mekhanicheskih ehkskavatorov s pryamoj lopatoj R YU Podehrni P Bules Gornyj zhurnal 2015 1 S 5561

15. Strabykin N N Osnovnye napravleniya tekhnicheskoj politiki v oblasti razvitiya ehkskavatorostroeniya dlya karerov N N Strabykin V M Goryachkin Gornoe oborudovanie i ehlektromekhanika 20123 S 3644

16. Litvin O I Obosnovanie racionalnyh tekhnologicheskih parametrov proizvodstva vskryshnyh rabot obratnymi gidravlicheskimi lopatami na razrezah Kuzbassa dis kand tekhn nauk Kemerovo $2012119 \mathrm{~s}$

17. Litvin O Study of the backhoe s digging modes at rock face working out O Litvin V Makarov A Strelnikov E Tyuleneva E3S Web of Conferences 2019 Vol 105 Article no 01024

18. Kantovich L I Opyt i perspektivy primeneniya gidravlicheskih ehkskavatorov pri otrabotke uglenasyshchennyh zon na razrezah Kuzbassa L I Kantovich O I Litvin A A Horeshok E A Tyuleneva Gornyj informacionno analiticheskij byulleten nauchno tekhnicheskij zhurnal 20194 S 152160

19. Tyulenev M A Ob intensivnosti izmeneniya proizvoditelnosti avtonomnoj tyazheloj platformy M A Tyulenev S O Markov D M Dubinkin V V Aksenov Vestnik KuzGTU 2021 1 C 97108

20. Dubinkin D M Vliyanie gornotekhnicheskih faktorov na proizvoditelnost bespilotnyh karernyh avtosamosvalov D M Dubinkin V V Aksenov M A Tyulenev S O Markov Tekhnika i tekhnologiya gornogo dela 2020411 S 4269

\section{Библиографическое описание статьи} Хорешок А.А., Дубинкин Д.М., Марков С.О., Тюленев М.А. Оценка степени взаимовлияния вместимости ковша экскаватора и кузова автосамосвала // Вестник Кузбасского государственного технического университета. 2021. - № 3 (145). - C. 104-112.

\section{Reference to article}

Khoreshok A.A., Dubinkin D.M., Markov S.O., Tyulenev M.A. Estimation of the degree of mutual influence of the excavator bucket capacity and haul truck body. Bulletin of the Kuzbass State Technical University, 2021, no.3 (145), pp. 104-112. 